Nuestro pesar nuestra aflicción, tunetuliniliz, tucucuca, Memorias en lengua náhuatl enviadas a Felipe II por indigenas del Valle de Guatemala hacia 1572, Paleografía, traducción, ensayos y notas de Karen Dakin, introducción y notas históricas de Cristopher H. Lutz, UNAM, Instituto de Investigaciones Históricas y Centro de Investigaciones Regionales de Mesoamérica, México, 1996, 209 pp.

\section{El libro}

Esta obra es la publicación, crítica y comentada, de 22 documentos originales encontrados en el Archivo General de Indias en Sevilla. Se trata de "Memorias" o cartas redactadas en el año de 1572 por indígenas de Guatemala, que se dirigieron al rey Felipe II suplicándole remediar sus sufrimientos. Los textos están escritos en náhuatl. Cada Memoria se publica en tres formas: primero se reproduce en facsímile, segundo en transcripción paleografiada en náhuatl y finalmente en traducción al castellano. Además, los documentos llevan más de 40 páginas de notas explicativas, tanto lingüísticas como históricas. Por ello esta manera cuidadosa de editar textos permite aclarar dudas y emprender nuevas investigaciones.

El libro nos obsequia los resultados de colaboración de un equipo interdisciplinario, aunque pequeño. El historiador Cristopher Lutz y la lingüista Karen Dakin analizan y comentan los textos, cada uno desde su especialidad.

Así, la edición contiene, además, estudios introductorios y ensayos adicionales. Una introducción histórica, de unas 50 páginas, nos sitúa en el contex- to de la segunda mitad del siglo XVI, especifica quiénes eran las personas señaladas en las cartas e identifica los pueblos y barrios cuyos habitantes redactaron los documentos. También presenta un breve resumen sistematizado de los agravios que los suplicantes exponen en sus peticiones al rey. Tres mapas señalan la ubicación de estos lugares, todos muy cercanos a la ciudad de Santiago, en aquel momento sede de la Audiencia de Guatemala, hoy llamada Antigua.

Por cierto, esta introducción histórica es sumamente útil para entender el contenido de los documentos presentados. Otro tanto debe decirse sobre los comentarios y análisis lingüísticos que explican cómo se desenredaron problemas de paleografía, ofrecen un listado de las abreviaturas y cómo se desataron, precisan cómo ciertas palabras castellanas fueron incorporadas al náhuatl aplicándoles sufijos derivativos del náhuatl. También se señalan influencias del griego y del latín eclesiástico. Se examina la estructura de las cartas, se comentan las firmas y se identifican los autores. Para comprender la retórica empleada en las Memorias, Karen Dakin la ejemplifica con traducciones literales como la siguiente: 
$\mathrm{Y}$ afligen mucho a los macehuales, que allá los pegan, los arrastran por el cabello, los golpean, los azotan con mecates y trabajan día y noche. Nadie descansa. ${ }^{1}$

\section{O esta otra cita de la Memoria 18:}

Aquí es nuestro daño que contamos, aquí se dirán las palabras de nosotros los alcaldes. Es mucho lo que sufrimos. No había quién nos tuviera piedad. ${ }^{2}$

En la última parte del libro se agregan Estudios Lingüisticos. Un extenso Estudio del léxico de las cartas agrupa los términos por tema, lo que permite destacar varios aspectos de la organización de la vida bajo el régimen colonial en aquella etapa. También es posible observar algo de "la evolución semántica que sufre el náhuatl al entrar en contacto con el español." Ahí creo que hubiera sido interesante tomar en cuenta que el náhuatl utilizado en Guatemala en 1572 también había entrado en contacto con lenguas mayas de la región, cuya influencia podría tal vez explicar el cambio del tl al t, y no solamente considerar el efecto pipil. $^{3}$

Finaliza el libro con un acucioso ensayo sobre $E l$ náhuatl de las Memorias: los rasgos de una lingua franca indigena. Este notable estudio, que compara la lingua franca con el náhuatl clásico y sus áreas dialectales, demuestra que los redactores de las cartas no eran hablantes nativos del náhuatl.

En efecto, las cartas fueron redactadas por quichés, cakchiqueles y otros mayas de Guatemala. Luego pidieron a un tal Juan Pedro traducirlas al náhuatl, aunque parece que éste no fue el único traductor. A lo menos la letra de las cartas varía y firman escribanos diferentes. Luego las Memorias fueron enviadas a fray Sebastián de Oviedo, un fraile dominico que había llegado a Guatemala hacía 20 años. ${ }^{4}$ Éste, al regresar a España, las llevó a Sevilla y las entregó al licenciado
Francisco Brizeño, ex-gobernador de Guatemala durante los años en que la Audiencia había sido trasladada a Panamá. Brizeño añadió una carta de presentación para el presidente del Consejo de Indias, escrita en Sevilla el ańo siguiente de 1573.

Las Memorias llegaron efectivamente a su destino, ya que si no no pudieran conservarse actualmente en el Archivo General de Indias. No obstante, lo más probable es que allá nunca fuesen leídas. ¿Quién en España hubiera entendido el náhuatl?

\section{El contenido}

La importancia de las Memorias no se agota de manera alguna en proveernos con un material para ejercicios eruditos sobre la lengua náhuatl. ¿De qué hablan estos documentos?

Nos presentan un cuadro que pinta en colores fuertes la vida cotidiana de pueblos mayas cercanos a la sede de la Audiencia de Guatemala, máxima autoridad colonial en Centro América. Los autores, que vivían en los barrios de la ciudad de Santiago o en poblados del propio valle, habían sido esclavos durante los conflictos bélicos. Después de ser liberados en tiempos del presidente Cerrato, se asentaron en terrenos pertenecientes a colonos españoles, donde trabajaban pagando terrazgo al propietario. Entre estos mayas había cakchiqueles, quichés y otros provenientes de regiones más lejanas. Cada poblado tenía su propio Cabildo indígena con sus alcaldes $y$ regidores. Fueron éstos quienes redactaron la mayoría de las Memorias, junto con otros ancianos de su pueblo. Por ser los responsables de entregar puntualmente los tributos asignados y ejecutar otras órdenes recibidas de autoridades españolas, eran también los más castigados cuando no podían cumplir.

\footnotetext{
'Memoria 4, p. LVIII.

${ }^{2}$ Ibidem.

${ }^{3}$ Memoria 12, nota 1, p. 112.

${ }^{4}$ El nombre de fray Sebastián de Oviedo figura entre los seis que llegaron en 1552. Véase María Milagros Ciudad Suárez, Los dominicos, un grupo de poder en Chiapas y Guatemala, siglos XVI y XVII, CSIC, Sevilla, 1996, p. 55.

Estudios de Cultura Maya. Vol. XXII, 2002

Instituto de Investigaciones Filológicas/

Centro de Estudios Mayas, UNAM

ISSN 0185-2574
} 
Sus quejas no se dirigen contra los españoles en general. $\mathrm{Al}$ contrario, confían en algunos de los frailes, tanto franciscanos como dominicos. También tienen aprecio por el licenciado Brizeño cuya tasación de tributos consideran justa, pues sólo entraban en el padrón los sanos que podian trabajar. Por ello también se dirigen a él para que interceda por ellos ante el monarca. Tampoco se quejan de los encomenderos cuyos excesos, en la primera etapa de la $\mathrm{Co}-$ lonia, son tan conocidos por las denuncias de fray Bartolomé de Las Casas. Treinta años más tarde, las peores injusticias fueron perpetradas por altos funcionarios de la Corona, es decir, por el gobierno mismo. En efecto, cuando la Audiencia después de estar en Panamá se reinstaló en Guatemala en 1570, abultando el aparato administrativo, se volvieron insoportables las aflicciones sufridas por la población. En particular resultó abusivo el licenciado Valdés de Cárcamo, uno de los oidores, cuyo ejercicio de poder, negocios turbios y maltratos, parecían haber opacado cualquier sentimiento de humanidad.

Este magistrado visitó los poblados del valle de Guatemala en 1572 e hizo un censo para la nueva tasación de tributos y asignación de trabajos obligatorios. Los alcaldes, regidores $\mathrm{y}$ alguaciles de los pueblos siempre habían estado exentos de pagar tributos durante el año que ocupaban su cargo. Pero Valdés los incluyó en la lista de tributarios y, además, todos tuvieron que trabajar. Nadie permaneció reservado, ni siquiera los enfermos. Los del barrio de Santo Domingo así lo expresaron:

A algunos que son muy viejos y pobres y mancos y cojos y ciegos y tullidos, no nos atrevemos a cobrarles, y por esta causa nos prenden y nos echan en la cárcel hasta que se cobrase. $^{5}$

Alcaldes y regidores fueron amenazados con "200 azotes de mecate", encarcelamiento y destierro si no obedecían. También sabían que en la cárcel se empleaba a los negros para golpearlos.
Con amargura contaron los cakchiqueles, de la Ciudad Vieja, que los papeles que certificaban la ayuda que ellos habían prestado a los españoles durante la Conquista les fueron quitados. Por su cercanía a la ciudad estaban sobrecargados de trabajos. Cada día debían llevar 20 cargas de leña a la capital, barrer allá las calles, barrer el Camino Real, trabajar en la construcción del acueducto sin que se les pagase. Por ello ya no podían cuidar su propio pueblo. "Nadie tiene ni capa ni huipil. Andan mal vestidos. Duermen en tablas y en la tierra". ${ }^{6}$ Además, "como algunos de los trabajadores murieron, nosotros tenemos que pagar su tequio de los muertos, y por eso nos encarcelan una o dos semanas. Luego nos piden una multa".

Otros pueblos, además de pagar tributo, tuvieron que entregar rastrojo para los caballos, trabajar en las calles, en las milpas de maíz y en los cañaverales de azúcar. "Ahora lloran mucho por tristeza"?

Obviamente, ser elegido para ocupar un cargo en los cabildos indígenas no era una oportunidad para enriquecerse, sino para ser castigado. La suerte de estas autoridades locales no era nada envidiable y era peor en las partes cercanas a la ciudad. Semejantes quejas se conocen por otros documentos referentes a Chiapa, en que también los más afligidos eran los poblados más cercanos a la capital provinciana Ciudad Real, por ejemplo los de Chamula.

Sin embargo, las Memorias aquí presentadas añaden otro desconsuelo que no he visto en documentación de Chiapa, y éste se refiere al negocio con los niños. La mayoría de las cartas del valle de Guatemala habla de esta amarga experiencia. El oidor Valdés aprovechando una orden para que los huérfanos aprendiesen un oficio, se llevó a la fuerza muchos niños de los pueblos - en un caso se mencionan 60 niños- y los vendió en la ciudad a los españoles, quienes le pagaron seis reales de plata por cada muchacho. $^{8}$

\footnotetext{
${ }^{5}$ Memoria 19, p. 73.

${ }^{6}$ Memoria 7, p. 33.

${ }^{7}$ Memoria 17, p. 65.

${ }^{8}$ Memoria 12, nota 9, p. 112.
}

Estudios de Cultura Maya. Vol. XXII, 2002

Instituto de Investigaciones Filológicas/

Centro de Estudios Mayas, UNAM 
Los de Santa Ana escribieron:

Siempre venden a nuestros hijos a los señores. Cada semana se venden 26 o 30 únicamente por mandato de Valdés. Meten al alcalde a la cárcel si no dan sus hijos para que los vendan. ... Todos los niños huérfanos se vendieron. Ya sabe usted cuánto nos hacen sufrir los oidores.

Obviamente el magistrado español tuvo otro concepto de "huérfano" que los pueblos mayas, que trataron de recuperar a "sus" niños y niñas. Pero para conseguirlo, tuvieron que pagar: A ello se refirieron, por ejemplo, los de Santo Domingo diciendo:

El licenciado Valdés dio a nuestros hijos e hijastros a los españoles aquí, y algunos fuimos testigos de eso... En cuanto a los niños $y$ niñas pequeños que iba a vender, entre todos debemos dar 200 tostones de una vez y por cada tostón se hace un mandato mediante el cual sale un niño. También por cada tostón el alguacil español, llamado Torres, va para sacar al nińo de la casa de españoles. Ahora algunos no salen, no los quieren entregar los españoles. ${ }^{10}$

No se trata aquí de anécdotas o delitos cometidos por algún individuo alguna vez, sino de injusticias per-

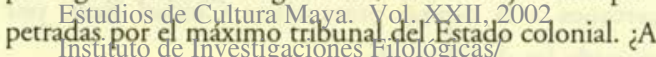

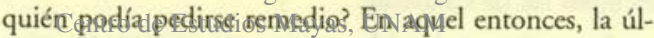

tima esperanza era reclamar al monarca mismo, y así lo hicieron aquellos pueblos mayas.

Muchas preguntas surgen a partir del cuadro que pintan estas Memorias. Por ejemplo, puede dudarse si la conocida merma demográfica que persistía a lo largo del siglo Xvı se debía primordialmente a las enfermedades causadas por microbios traídos de Europa. O jacaso fuese una estructura socio-política que propiciaba el aniquilamiento de un sector de la población?

Por cierto, este libro no trata solamente de aumentar nuestros conocimientos acerca de asuntos del pasado. Por ello quiero finalizar este comentario con el texto que Karen Dakin y Cristopher Lutz pusieron como dedicatoria de esta obra:

Dedicamos esta obra a nuestros colegas y amigos mayas guatemaltecos y a todos los grupos indígenas de las Américas que durante más de quinientos años han protegido y luchado por la defensa de sus derechos frente a opresores. Con tristeza, notamos que también hay que recordar que las Memorias que aquí presentamos son muy similares a diversas publicaciones indígenas que están apareciendo hoy en día, no sólo en Guatemala, sino en todas partes del continente americano, en protesta a las violaciones de derechos humanos e incursiones territoriales perpetradas en contra de sus poblaciones. Esperamos que nuestro pequeño esfuerzo anime a los que siguen esta lucha. 